\title{
El nacionalismo minoritario, de la marginalidad al gobierno: la trayectoria del Bloque Nacionalista Galego (1982-2007)*
}

\author{
Margarita Gómez-Reino Cachafeiro \\ Universidad de Santiago de Compostela \\ Departamento de Ciencia Política y de la Administración \\ mgreino@usc.es
}

\section{Resumen}

¿Cómo se explica la evolución de un partido nacionalista minoritario, de la marginalidad política al gobierno? La tercera ola de movilización nacionalista en Europa definió un nuevo espacio político para partidos nacionalistas sin representación política previa. Este artículo analiza esta trayectoria, desde los fracasos iniciales hasta el gobierno, utilizando el caso del BNG en Galicia. Se define, en primer lugar, el «ciclo vital» del partido en sus distintas fases de desarrollo, desde las posiciones antisistema hasta su participación en el gobierno autonómico. Posteriormente, se explica el impacto de estos procesos, tanto en las dinámicas internas y organizativas, como en los objetivos perseguidos por el partido a lo largo de su trayectoria. En síntesis, las decisiones sobre los objetivos partidistas fueron decisiones «blandas» de adaptación gradual al contexto político e institucional, pero transformaron la identidad y la dinámica organizativa del partido.

Palabras clave: partidos nacionalistas, partidos minoritarios, ciclo vital de los partidos, cambios organizativos, objetivos partidistas e intercambios.

\section{Abstract. Explaining change within parties: the $B N G$ and its trajectory from marginality to government (1982-2007)}

What implications does the evolution of minor nationalist parties from marginality to government for party internal dynamics? The third wave of nationalist mobilization in Europe defined a new political space for nationalist parties without previous political representation. This article analyzes this specific trajectory, from initial failures to government, using the case of the Galicia BNG. It explains the impact of expanding political space for internal party dynamics and organization, as well as reshaping party objectives over time. In short, decisions about party objectives were 'soft', of gradual adaptation to the institutional and political context, yet they radically transformed the identity and organizational dynamics of the BNG.

Key words: nationalist parties, minority parties, party lifespan, organizational change, party goals and trade-offs.

* Una parte de este artículo se presentó en su primera versión en el congreso «From protest to institutions: minority nationalist parties and the challenges of political representation» («De la protesta a las instituciones: los partidos nacionalistas y los retos de la representación política»), celebrado en la Universidad de Aberystwyth (Gran Bretaña), del 27 al 29 de octubre de 2006. 


\section{Sumario}

Introducción

El marco conceptual: partidos minoritarios, trayactorias y cambios

El ciclo de vida del BNG (1982-2007)
Cambios en la organización del partido

Camios en los objetivos del partido

Conclusiones

Bibliografía

\section{Introducción}

Uno de los retos en el análisis de los partidos nacionalistas en Europa es su naturaleza y su presencia heterogénea, entre la marginalidad o el éxito electoral, las tendencias antisistémicas o proinstitucionales, su carácter de partidos de oposición o de gobierno. Algunos de estos partidos se pueden considerar mayoritarios (mainstream), o partidos catch-all ('atrápalo todo') en su forma de politizar temas y en su dinámica competitiva (De Winter, 1998: 223), pero otros subsisten como partidos políticos marginales. La evolución de los partidos en uno u otro sentido no es sólo una cuestión de éxito electoral. Para muchas formaciones nacionalistas, la institucionalización y la "normalización» en un sistema de partidos puede implicar una serie de retos y ajustes, con sus beneficios y sacrificios internos.

El Bloque Nacionalista Galego (BNG) es un caso relevante para examinar la trayectoria de un partido nacionalista desde la marginalidad política hasta el gobierno. El ciclo vital del BNG ejemplifica el paso de ser una fuerza marginal antisistémica en los años ochenta, a ser un miembro del actual gobierno de coalición gallego formado en 2005. En sus dos décadas de existencia, el BNG ha seguido una trayectoria bastante lineal que ha distanciado al partido de sus orígenes ideológicos y organizativos, lo cual ha transformado su dinámica interna y sus objetivos. ¿Cómo se explica esta trayectoria del BNG, de la marginalidad al gobierno autonómico, y cuáles son sus consecuencias principales? Este artículo examina el ciclo vital de la formación, siguiendo sus pasos por los diversos umbrales de su desarrollo político, analizando los objetivos y las decisiones de los dirigentes del partido de forma secuencial. Se examinan los cambios externos e internos que influyeron en la adaptación de la organización del partido y de sus objetivos a un nuevo contexto político e institucional.

\section{El marco conceptual: partidos minoritarios, trayectorias y cambios}

La literatura especializada define tres olas de éxito político y electoral de los partidos nacionalistas; la tercera ola corresponde a la etapa que comienza en 1970 , con la proliferación de nuevos partidos y su creciente relevancia política (Müller-Rommel, 1998). Este reciente éxito electoral se explica utilizando el concepto de «emprendedores étnicos», en referencia a la naturaleza de estas formaciones como movilizadoras de identidades políticas (Türsan, 1998: 6). La tercera ola define un nuevo espacio político para los partidos nacionalistas en 
Europa en el que se vincula su oferta política (la política de identidad) con las nuevas estructuras de oportunidades políticas que surgen ante la erosión de los clivajes tradicionales.

El concepto de "partidos nicho" permite relacionar los partidos nacionalistas con otros nuevos partidos de familias de partidos ecologistas o de la nueva derecha radical, en referencia a sus características y estilos competitivos comunes. Los partidos nicho, en contraste con los partidos de corriente mayoritaria, exhiben tres características clave: un alejamiento de la política tradicional, una temática política novedosa y la politización de un restringido conjunto de temas (Meguid, 2005: 347-348; Adams y otros, 2006). Resulta complicado aplicar este concepto a los partidos de la familia nacionalista. Por un lado, algunos partidos nacionalistas pueden ser considerados como partidos tradicionales y como "partidos que son intrínsecamente catch-all» ('atrápalo todo') en su forma de politizar temas y en sus dinámicas competitivas (De Winter, 1998: 223). Por otro lado, aunque se puedan establecer las categorías de partidos "nicho" y "de corriente mayoritaria», la naturaleza de las distintas formaciones puede cambiar en distintos contextos. Factores exógenos y endógenos pueden determinar que los partidos actúen de un modo u otro. Este tipo de análisis no ofrece las herramientas necesarias para entender si o cómo los partidos pasan de nichos a mayoritarios en sus dinámicas competitivas.

Más allá de la dimensión competitiva y electoral, los partidos nacionalistas también tienen que adaptarse a nuevos entornos institucionales. Así, y en particular en relación con los nuevos partidos ecologistas, la literatura sobre partidos pequeños (small parties) se plantea el análisis del papel y del funcionamiento de éstos en el gobierno y sus consecuencias internas. Esta línea de investigación se centra en el funcionamiento de los partidos pequeños como organizaciones dinámicas (Müller-Rommel, 2002). El análisis se basa no sólo en los resultados electorales de los partidos pequeños, sino también en sus resultados parlamentarios y su adaptación al contexto político e institucional. La trayectoria representa el recorrido de los partidos ecologistas en perspectiva comparada en Europa.

El rendimiento político de los nuevos partidos puede analizarse a través de un marco conceptual elaborado por Pedersen, que describe y explica las maneras como cambian los partidos políticos (1982). Para ellos, se utiliza la metáfora biológica en la noción del "ciclo vital de los partidos» que trata la evolución de los partidos políticos como organizaciones que se asemejan a «seres mortales» (Pedersen, 1982, 1991). En el marco conceptual de Pedersen, los partidos superan ciertos umbrales en un continuo que plasma las diversas fases del ciclo de vida de un partido: en primer lugar, aparece el umbral de declaración: un grupo anuncia que participará en las elecciones. En segundo lugar, se define el umbral de autorización: un grupo cumple los requisitos legales y otros requisitos necesarios para poder participar en unas elecciones. En tercer lugar, se sitúa el umbral de representación: un partido cumple las condiciones necesarias para obtener escaños en el parlamento. En cuarto lugar, se analiza el umbral de relevancia, tanto como potencial de chantaje (otros partidos polí- 
ticos responden a éste), como potencial de coalición. En último lugar, se analiza el umbral de gobierno: cuando un partido es capaz de entrar a formar parte del gobierno. Así, el rendimiento de un partido se evalúa mediante etapas de desarrollo marcadas por diferentes umbrales.

La secuencia no tiene que ser necesariamente lineal y debe completarse con un análisis de las transformaciones que se producen a medida que un partido busca compaginar objetivos de diversa índole en cada una de sus fases de desarrollo. Según Müller y Strom, todos los partidos tienen tres objetivos básicos: consecución de votos, obtención de cargos públicos y aplicación de sus políticas públicas (Müller y Strom, 1999: 5). En este marco analítico, los partidos no alcanzarían todos los objetivos de forma simultánea y tendrían que hacer ajustes y concesiones entre diversos objetivos, pues los partidos se enfrentan a «decisiones difíciles, dolorosas y con consecuencias» (Müller y Strom, 1999: 10). Los principales factores que limitan las decisiones de los partidos pueden ser internos (aspectos organizativos, como, por ejemplo, las limitaciones impuestas a sus líderes) o bien externos (el entorno institucional y el contexto en el que funcionan) (Müller y Strom, 1999). Así, el rendimiento institucional y la «normalización» en los sistemas de partidos conllevan una serie de retos y ajustes entre objetivos básicos a medida que se van superando diferentes fases en el desarrollo de los partidos. Los cambios organizativos y los cambios en los objetivos se explican como resultado de las dinámicas que se producen en las fases de desarrollo del partido.

\section{El ciclo de vida del BNG (1982-2007)}

El BNG mostró, durante la mayoría de sus veinticinco años de existencia, una tendencia lineal de expansión y consolidación en elecciones autonómicas, estatales y europeas. La expansión electoral del partido en estos tres niveles tuvo lugar en paralelo, aunque los mejores resultados siempre se han obtenido en las elecciones autonómicas. En las elecciones de 2001, se estancó ese crecimiento y luego disminuyó claramente en las elecciones autonómicas de 2005. El reciente declive electoral que ha experimentado el BNG se ha hecho evidente en los tres niveles territoriales (Gómez-Reino, 2006; Lago y Lago, 2006). Durante la etapa de 1982 a 2005, el BNG pasó por diversos umbrales del ciclo

Tabla 1. El ciclo de vida del BNG: los umbrales

\begin{tabular}{lccc}
\hline Umbral & Nivel autonómico & Nivel estatal & Nivel europeo \\
\hline I Declaración & 1982 & - & - \\
II Autorización & 1982 & 1996 & 1999 \\
III Representación & 1985 & - & - \\
IV Potencial de «chantaje» & 1997 & - & - \\
IV B Potencial de coalición & 2005 & - \\
V Gobierno &
\end{tabular}

Fuente: elaboración propia. 
vital definido por Pedersen. La tabla 1 resume la trayectoria de los umbrales traspasados, así como también la fecha y la secuencia en las que fueron alcanzados en los distintos niveles.

Se alcanzó el umbral de representación autonómico en 1985, cuando Xosé Manuel Beiras consiguió un escaño en el Parlamento de Galicia. El BNG tardó mucho más en cruzar los umbrales de representación a nivel estatal (1996) y europeo (1999). El nivel de representación a nivel estatal no se alcanzó hasta una década más tarde, en las elecciones generales de 1996, cuando el BNG obtuvo dos escaños en el Congreso. Desde entonces, este partido ha tenido siempre una presencia en el Parlamento. En el 2000, llegó a ocupar tres escaños; en la actualidad, cuenta con dos diputados.

Una posible explicación del retraso en obtener representación a nivel estatal y europeo se halla en el hecho de que, para muchos partidos nacionalistas, el escenario estatal y el europeo tienen una importancia secundaria (Reif y Schmitt, 1980). No obstante, las diferencias en los resultados del BNG de cara a los umbrales de representación a nivel autonómico, estatal y europeo obedecen, por un lado, a la estrategia interna del partido, centrado en sí mismo y en la política gallega, pero, por otro lado, a los efectos producidos por variables institucionales, fundamentalmente el sistema electoral. A nivel estatal, las dificultades a las que se enfrentó el BNG a la hora de superar el umbral de representación estatal están ligadas al menor interés mostrado por el partido en competir en la política española y al impacto del sistema electoral, sobre todo en las provincias de Ourense y Lugo (Lago y Lago, 2006). En primer lugar, la magnitud de los distritos electorales varía de las elecciones generales a las autonómicas, pues en éstas la proporcionalidad entre votos y escaños es alta, mientras que en las elecciones generales resulta más difícil obtener escaños ${ }^{1}$. En segundo lugar, la existencia de un sistema político multinivel en España ha llevado a que se produzcan varias pautas distintas de competición electoral y voto estratégico, con el surgimiento del voto dual, que se ha estudiado sobre todo en el caso catalán (Pallarés y Keating, 2003; Riba, 2000; Fraile y PérezNievas, 2000; Montero y Font, 1991) ${ }^{2}$.

1. Los umbrales electorales efectivos de las provincias de Lugo y Ourense (12\%) son mucho más altos en las elecciones generales que en las autonómicas (5\%) (Lago y Lago, 2006: 18-20).

2. El voto dual se refiere a dos temas que están interrelacionados: por una parte, se refiere a la transferencia de votos entre elecciones autonómicas y generales, que tiene lugar entre partidos con y sin representación a nivel estatal (principalmente con un trasvase de votos hacia los partidos estatales en las elecciones generales). Aunque existe poca evidencia de que tenga un impacto sustancial en Galicia, algunos estudiosos del tema han indicado que el voto dual se da entre el BNG y el PSOE (Rivera y otros, 1997: 295-297). Por otra parte, la política multinivel afecta a la participación electoral, ya que se da una "abstención diferencial», es decir, existen diferencias sistemáticas en la participación electoral dependiendo del tipo de elecciones. La tasa de participación varía entre elecciones autonómicas y generales, pues los votantes se vuelcan menos en las autonómicas. Además, este comportamiento se acentúa en el caso de determinados partidos, como, por ejemplo, el voto al Partido Socialista 
A nivel europeo, las dificultades a las que se enfrentó el BNG para poder superar el umbral de representación fueron mucho mayores que a nivel estatal. Sólo llegó a superar este umbral en 1999, y únicamente durante la etapa de 1999 a 2004, pues, en las elecciones europeas de 2004, el BNG no obtuvo escaño alguno. Una vez más, la explicación se halla directamente ligada, por un lado, al hecho de que el partido ha puesto menor énfasis en estas elecciones y ha mostrado una actitud negativa hacia la Unión Europea (UE) y, por otro lado, al impacto y a los efectos del sistema electoral ${ }^{3}$. Esto complicó aún más la situación para los partidos nacionalistas y provocó que fuera más difícil obtener representación, por lo que tienen menos presencia en el Europarlamento, con una media de entre uno y tres escaños ${ }^{4}$. Por otra parte, el BNG es claramente un partido euroescéptico y, aunque ha ablandado su postura sobre la UE, el nivel europeo de representación ha desempeñado un papel menor (Elías, 2005; Llamazares, Gómez-Reino, Ramiro, 2007). En las elecciones europeas, el BNG ha seguido, a lo largo del tiempo, una estrategia de aislarse de las distintas coaliciones alternativas que se fueron formando entre partidos nacionalistas $^{5}$. La primera coalición electoral del BNG, para las elecciones europeas del 2004, fue con dos partidos nacionalistas que gobernaban en sus comunidades autónomas: CiU y PNV.

En relación con los umbrales de relevancia y gobierno en el nivel estatal y europeo, el BNG nunca los ha superado hasta la actualidad. A nivel estatal, nunca ha alcanzado el umbral de relevancia y nunca ha tenido potencial de coalición o influencia, a diferencia de los otros partidos nacionalistas de las nacionalidades históricas (PNV, CiU y ERC). Los votos de estos partidos pueden resultar cruciales cuando el Gobierno central no posee una mayoría absoluta y necesita aprobar alguna ley. En cambio, el BNG nunca ha influido por separado en la agenda política estatal, más bien ha usado su representación en el Congreso para desempeñar un papel expresivo, denunciando el impacto negativo del Estado español en Galicia, protestando con-

(Riera, 2007). En Galicia, la abstención diferencial no es tan trascendental como en Cataluña y Euskadi, pero sí afecta sobre todo a los votantes de partidos estatales, ya que los votantes del Partido Socialista muestran una mayor desmovilización en las elecciones autonómicas y, en cambio, se movilizan para votar en las generales (Lago, 2000: 91).

3. En España, el problema más frecuente con el que se topan los partidos nacionalistas es el tamaño de las circunscripciones electorales (un único distrito electoral estatal), que les fuerza a formar coaliciones para obtener representación. En las elecciones europeas de 2004, aparte del distrito electoral único, el número de escaños asignados a España en el Parlamento Europeo se redujo de 64 a 54, tras la entrada en la UE de nuevos miembros.

4. De manera excepcional, y sólo en las elecciones europeas de 1999, llegó a haber siete eurodiputados nacionalistas.

5. En parte, esto se debe a divisiones internas sobre qué coalición y qué partidos serían compañeros aceptables. Algunos grupos dentro del partido han expresado su preferencia por coaliciones con partidos nacionalistas que estén gobernando, y otros prefieren coaliciones nacionalistas de izquierdas. 
tra la situación económica y defendiendo los intereses de Galicia de cara al Gobierno central. De todos modos, desde que alcanzó el umbral de representación estatal (1996), el BNG ha buscado mejorar su estatus institucional y político en este nivel y, por ello, ha tenido interés en potenciar la alianza Galeusca $^{6}$. Los resultados de Galeusca a nivel europeo han sido limitados, ya que no se alcanzó la representación y los partidos miembros mantienen posiciones muy dispares con respecto a la Unión Europea. En las elecciones europeas de 2004, Galeusca se convirtió en una coalición electoral que por sólo un puñado de votos no obtuvo representación para el BNG. A nivel de la UE, el único eurodiputado del BNG, Camilo Nogueira (1999-2004) se integró en la Alianza Libre Europea (ALE) y participó en el grupo parlamentario de los verdes. Su trabajo fue principalmente de «normalizar» la postura del BNG de cara a la UE, y su influencia política dentro de la ALE resultó ser limitada. En definitiva, su papel e influencia en la agenda política a nivel estatal y europeo han sido limitados, aunque estos niveles resultaron cada vez más importantes para la estrategia del partido desde finales de la década de los noventa.

\section{El ciclo vital del partido en el nivel autonómico}

El ciclo de vida del BNG ha estado determinado principalmente por las dinámicas del partido a nivel autonómico. Los umbrales de declaración, autorización y representación fueron superados entre 1982 y 1985. Tras la transición española a la democracia, y antes de cruzar el umbral de declaración en 1982, hubo una serie de intentos fallidos por organizar partidos nacionalistas en Galicia. Estos partidos nacionalistas fueron marginales electoral y políticamente durante el periodo que va de 1975 a 1982 (Máiz, 1996; Beramendi y Núñez Seixas, 1996) ${ }^{7}$. Tras los fracasos iniciales, se llevaron a cabo una serie de iniciativas encaminadas a unificar el nacionalismo gallego para obtener representación política a nivel autonómico, como el Bloque Estatal-Popular

6. Simbolizando la solidaridad de los nacionalistas contra el Estado español, esta alianza de partidos nacionalistas en las «nacionalidades históricas» del Estado español surgió por primera vez en 1923 (Beramendi y Núnez Seixas, 1996). El 16 de julio de 1998, el BNG, junto con PNV y CiU, firmaron la Declaración de Barcelona, una agenda política común para transformar el Estado español en un estado plurilingüe, multicultural y pluriestatal. Esta declaración constituyó un paso importante para el BNG a nivel estatal, que buscaba influir así en la agenda política española en conjunción con sus aliados, dos partidos de mucho mayor peso político e institucional, para así coordinar estrategias electorales, políticas e institucionales a nivel estatal.

7. A diferencia de los partidos nacionalistas de Euskadi y Cataluña, que obtuvieron unos resultados electorales suficientes como para darles representación y acceso al gobierno autonómico, los partidos nacionalistas gallegos se quedaron sin presencia institucional durante los primeros años de la democracia española. Una de las principales causas de su marginalidad electoral e institucional era la gran fragmentación y heterogeneidad de los partidos nacionalistas (Máiz, 1996). 
Galego $^{8}$. Partiendo de estos antecedentes, el Bloque Nacionalista Galego (BNG) nació como tal en 1982, y se constituyó como una organización frentista construida sobre los remanentes del BN-PG 9 . Dada la fragmentación de los nacionalistas gallegos, el objetivo de alcanzar la representación resultó ser un verdadero reto para todos los partidos nacionalistas de Galicia. El BNG superó el umbral de representación en 1985, cuando Xosé Manuel Beiras fue elegido al Parlamento de Galicia; ahora bien, éste no fue el único partido nacionalista gallego en cruzar el umbral de representación durante la década de los ochenta. Tras las primeras elecciones autonómicas, entraron en el Parlamento gallego dos partidos nacionalistas: el Bloque Estatal-Popular Galego (BN-PG) y Esquerda Galega (EG). En las siguientes elecciones, fueron tres los partidos nacionalistas con representación autonómica (BNG, EG y el Partido Galleguista (PG)), mientras que, en 1989, fueron otra vez dos los partidos nacionalistas que obtuvieron escaños (BNG y EG). Por lo tanto, durante la década de los ochenta, el BNG competía en el sistema político gallego con otros partidos nacionalistas.

Durante este periodo, el partido cruzó tres umbrales de representación distintos. El primer umbral fue conseguir representación en el Parlamento de Galicia, en 1985. El segundo umbral de representación, superado en 1989, supone que el BNG alcance el puesto de principal fuerza nacionalista gallega en escaños, con lo que se convierte en el punto de referencia del nacionalismo gallego. El tercer y último umbral de representación fue superado por el BNG en 1993, al convertirse en el único partido nacionalista con representación en el Parlamento de Galicia, debido al fracaso de los otros partidos nacionalistas. Estas tres etapas fueron condicionantes que facilitaron la expansión electoral y organizativa del BNG durante la década de los noventa.

La coordinación de los partidos nacionalistas gallegos bajo el paraguas del BNG constituyó un requisito indispensable para poder alcanzar, posteriormente, los umbrales de relevancia y gobierno. El umbral de relevancia depende de factores externos, de cambios en la estructura de oportunidades políticas que permitan la posibilidad de "chantaje» o de coalición (Sartori, 1976). Esta definición no permite definir un periodo concreto en el cual el BNG haya cruzado claramente el umbral de relevancia (potencial de coalición), ya que el Partido Popular obtuvo mayorías absolutas en Galicia entre 1989 y 2005. Sin embargo, ya desde las elecciones autonómicas de 1997, el BNG era visto como un posible socio para cualquiera de los dos partidos con representación estatal

8. El Bloque Estatal-Popular Galego (BN-PG) se formó en 1977 como una alianza para crear una organización de masas que unía la UPG con AN-PG —éste último era una plataforma de partidos. Dentro de la heterogeneidad de las fuerzas nacionalistas gallegas, el BN-PG constituyó una corriente concreta que se autodefinía como «nacionalismo popular» gallego (Beramendi y Seixas, 1996: 250).

9. La primera vez que se presentó a unas elecciones fue en las generales de 1982, con unos resultados modestos $(2,96 \%$ de los votos) y sin obtener escaños en el Parlamento español. 
—el PP y el PSdG. En 1997, el BNG se convertía en la segunda fuerza política gallega en términos de votos y escaños autonómicos, superando por primera vez al Partido Socialista. En un sentido más amplio, la relevancia también puede ser entendida en términos de conseguir influencia política sobre las pautas competitivas y las agendas políticas de los partidos y, en este sentido, el PSdG sufrió especialmente la creciente competitividad del BNG (Jiménez, 2003: 310). La moderación ideológica y el creciente éxito electoral del BNG contribuyeron a definir una nueva agenda política autonomista para el PSdG a finales de los noventa. El impacto del éxito del BNG sobre el PP no fue tan claro, ya que su rexionalismo se había acentuado desde 1989, bajo el liderazgo de Manuel Fraga (Lagares, 2003). En síntesis, a finales de los noventa, el BNG era considerado cada vez más como un posible aliado o competidor para los dos principales partidos de la política gallega.

El BNG cruzó finalmente el umbral de gobierno en 2005, con la formación de un gobierno bipartidista en coalición con el Partido Socialista (PSdG). La creciente fuerza electoral del BNG no constituye el principal factor explicativo de su entrada en el gobierno en 2005, dado que el partido mostraba ya un estancamiento electoral en las elecciones europeas (2004), generales (2004) y autonómicas (2005). De hecho, el BNG pasó de diecisiete a trece diputados autonómicos en 2005; no obstante, una serie de cambios en la estructura de oportunidades políticas desempeñaron un papel fundamental a la hora de situar al BNG en posición de partido bisagra en el sistema gallego de formaciones. Desde las elecciones de 1989, se avecinaba la posibilidad de dejar atrás la etapa de gobierno del PP, que llegó finalmente a perder su mayoría absoluta (Lago, 2006: 1) ${ }^{10}$.

El BNG en el gobierno de coalición desde 2005 consiguió obtener una vicepresidencia y cuatro consellerías (Cultura; Desarrollo Rural; Industria, Comercio e Innovación, y Vivienda). El programa de gobierno, o Programa Común (24 de julio de 2005), define cinco objetivos: mejorar la situación del empleo; invertir en capital humano, educación e investigación; fomentar el bienestar y las políticas sociales para favorecer la igualdad; desarrollar una política medioambiental y urbana, y promover la normalización lingüística (Texto do acordo definitivo BNG-PSdG, 2005). El pacto de gobierno también incluía un nuevo estatuto de autonomía de Galicia para alcanzar mayores niveles de autogobierno y el reconocimiento de Galicia como nación.

En resumen, el ciclo de vida del BNG ha seguido una trayectoria bastante lineal, puesto que ha cruzado de forma secuencial diversos umbrales, desde la declaración (1982) hasta alcanzar el gobierno (2005). Los principales avances en la trayectoria del BNG resultaron de cruzar los umbrales de represen-

10. También hace falta tomar en cuenta factores externos al sistema de partidos gallego, factores que facilitaban coaliciones a nivel autonómico entre nacionalistas y socialistas en diversas partes de España. En concreto, existía el antecedente de la coalición de gobierno en Cataluña, que se formó en 2003, y que incluía al Partido Socialista y a ERC. 
tación en 1985 y de gobierno en 2005. En esta evolución, el BNG muestra su capacidad de adaptación y una trayectoria bastante uniforme de partido nicho a partido "de corriente mayoritaria». El estancamiento electoral no impidió el éxito de cruzar el umbral de gobierno a nivel autonómico en 2005. De todos modos, catalogar la trayectoria del BNG como un proceso lineal y continuo sería una simplificación excesiva, pues sufrió incertidumbres y retrocesos en las dos décadas de su existencia, y esta evolución tuvo un impacto directo en la organización y en los objetivos del BNG.

\section{Cambios en la organización del partido}

La superación de los umbrales en los tres niveles territoriales tuvo un impacto directo en la organización del partido. La presión sobre el BNG para cambiar las estructuras internas de organización aumentó a medida que cruzaba sucesivos umbrales. Ahora bien, las presiones hacia el cambio no fueron equiparables en los distintos niveles territoriales. La tabla 2 resume la presión por el cambio en la estructura de organización del partido a medida que se han ido cruzando los diversos umbrales de los distintos niveles territoriales.

Tabla 2. Las presiones sobre la organización en las distintas fases

\begin{tabular}{lrrr}
\hline Umbrales/Niveles & Autonómico & Estatal & Europeo \\
\hline I. Declaración & Débil & Débil & Débil
\end{tabular}

II. Autorización 1982

Movilización vs. institucionalización.

Modelo asambleario.

Descentralización de la organización del partido:

división territorial por

comarcas.

III. Representación

Mediana

Débil

Débil

Expansión de la organización.

Expansión del número de afiliados.

División funcional y territorial.

Aumento del pluralismo interno:

representación de partidos y colectivos.

IVa. Relevancia

Mediana

Chantaje

IVb. Relevancia

Coalición

V. Gobierno

Fuerte.

Nuevo liderazgo.

Debilitamiento del pluralismo interno.

Eliminación del modelo asambleario. 
Los cambios organizativos en el BNG derivan, aquí también, de las presiones a nivel autonómico. Las presiones después de cruzar los umbrales de representación estatal y europeo iban claramente por detrás del nivel autonómico y fueron siempre mucho más débiles. Para superar el umbral de representación, en estos dos niveles surgieron una serie de presiones favorables a entrar en alianzas con otros partidos nacionalistas a nivel estatal, y a nuevas estrategias electorales y políticas para competir en elecciones generales y europeas. En contraste, las presiones derivadas de cruzar umbrales autonómicos de representación en las tres etapas ya delineadas llevaron a cambios importantes en la organización del partido, así como la secuencia posterior tras el paso por los umbrales de relevancia y gobierno a nivel autonómico.

El BNG cruza los umbrales de declaración y autorización en 1982 heredando la débil organización de los partidos que participaron en la fundación del BNG (UPG y PSG, sobre todo el primero) y, con ella, construye una nueva organización de partido (Vilas y Fernández Baz, 2004: 203-205). En primer lugar, este partido frentista había sido estructurado, no como una organización institucionalizada, sino como una plataforma para la movilización. A principios de los ochenta, el BNG titubeaba entre adoptar una estrategia frentista antisistema basada en la movilización directa, o bien decantarse por una estrategia de institucionalización. Este dilema fue resuelto en 1985, cuando, en una asamblea extraordinaria, el BNG decidió aceptar formalmente la Constitución española y el Estatuto de Autonomía. En segundo lugar, el BNG heredó un modelo asambleario de voto directo de los afiliados en asambleas del partido, tanto a nivel local como autonómico ${ }^{11}$. Este modelo es un punto clave de la identidad organizativa del BNG, y se mantuvo durante las dos décadas de expansión y consolidación del grupo nacionalista. Por lo tanto, la presión para introducir cambios en la organización del partido tras cruzar los umbrales de declaración y autorización se podrían catalogar como débiles.

En cambio, tras cruzar el umbral de representación en 1985, el impacto ya se hizo sentir en la organización del partido, pues empezaron a oírse voces que presionaban para que el colectivo frentista se institucionalizase. La III y la IV asambleas nacionales, celebradas en 1985 y 1987, respectivamente, llevaron al establecimiento de una clara división de labores a nivel funcional y territorial en la organización (Vilas y Fernández Baz, 2004). La presión para reforzar la organización del partido aumentó a medida que el BNG seguía su trayectoria de expansión electoral desde las elecciones autonómicas de 1989. Ahora bien, durante la etapa que abarca desde cruzar el umbral de representación (1985) hasta llegar a un cierto nivel de relevancia e influencia política en el sistema gallego de partidos (1997), las presiones a favor de cambios organizativos funcionaron de forma diferente. La superación del primer umbral de

11. Entre 1975 y 1982, surgieron varias alternativas políticas en el bando nacionalista, tales como el precursor del BNG, el BNPG, que seguía el modelo asambleario. Para una visión histórica de diversas iniciativas políticas que resultaron fallidas, véase Beramendi y Núñez Seixas, 1996. 
representación — con el logro de una presencia en el Parlamento de Galicia en 1985 - tuvo un impacto directo en los esfuerzos por consolidar la estructura organizativa, primero de una manera formal durante la década de los ochenta y luego de forma práctica durante los noventa. Estaba claro que se necesitaba una expansión de la organización — de sus estructuras y afiliados- junto con una organización centralizada en Galicia.

La superación del segundo umbral de representación, en 1989, que coloca al BNG en primera posición en escaños y votos entre los nacionalistas de Galicia, tuvo un impacto directo en la organización del partido, ya que llevó a la incorporación de otras alternativas nacionalistas a este colectivo frentista. La última serie de incorporaciones de partidos y colectivos tuvo lugar a principios de la década de los noventa (1991-1994), época en la que el BNG se consolidó como una única organización, a la vez que reconocía su naturaleza plural, con lo cual otorgó una cierta representatividad interna a los diversos partidos y colectivos (Gómez-Reino, 2006). La Asamblea Nacional de 1993 definió los criterios bajo los cuales otras formaciones podían incorporarse al $\mathrm{BNG}^{12}$. El peso real y el poder político de cada uno de estos colectivos varía; el partido más poderoso dentro del BNG — ya desde los primeros intentos por unir a los nacionalistas gallegos - ha sido la UPG. A nivel organizativo, se sigue considerando a la UPG como el esqueleto del BNG y su corriente dominante (Lago, 2004; Barreiro, 2003). Finalmente, la superación del último umbral de representación —al convertirse, en 1993, en el único partido nacionalista gallego con representación institucional- llevó a una ulterior consolidación de la organización de la coalición. Esto tuvo un impacto directo en la definición del modelo organizativo del BNG y en su estructura final, que se labró en 1995, en la VII Asamblea Nacional.

Durante los años noventa, cambió el marco de competición política entre los partidos nacionalistas gallegos. El BNG integró con éxito en una única estructura organizativa a varias otras fuerzas nacionalistas y, en consecuencia, desde 1993, el BNG ha sido el único partido nacionalista con representación parlamentaria en Galicia, lo cual ha influido en su organización interna. La importancia de cruzar el umbral de representación autonómica radica en el hecho de poder mostrar una estrategia de coordinación de las fuerzas nacionalistas (Lago, 2004; Gómez-Reino, 2006). Durante la década de los ochenta, esta situación se mantuvo en un punto muerto, mientras que, en los años noventa, el proceso concluyó con la incorporación de casi todos los partidos nacionalistas gallegos al BNG. Una serie de factores sistémicos llevaron a la concentración de los partidos nacionalistas en Galicia, factores como el esta-

12. Los estatutos que se aprobaron en diciembre de 1995, durante la VII Asamblea del BNG, celebrada en Ferrol, definían la figura legal que podían mantener estos grupos dentro del BNG (sección 2): cada partido tendría dos representantes en el Consello Estatal, la ejecutiva del BNG. La inclusión de diversos colectivos también implicaba de manera informal que los dirigentes de las diversas organizaciones estarían incluidos en las listas electorales del BNG (Lago, 2004: 53). 
blecimiento, en 1992, de un nuevo umbral electoral en las elecciones autonómicas, que pasó del 3 al 5\% de votos válidos (Lago y Lago, 2006: 20). La coordinación de los partidos nacionalistas gallegos fue el resultado de la interacción de un factor exógeno (la configuración del sistema de partidos gallego, con la creciente fuerza del BNG de cara a sus competidores nacionalistas) y un factor endógeno derivado de la naturaleza frentista del BNG, que, desde su génesis, integra una pluralidad de grupos (Lago y Lago, 2006: 39; Lago, 2004). La consecuencia más destacada de este proceso fue que los partidos nacionalistas gallegos alcanzaban la unidad a la vez que el BNG conseguía la exclusividad como representante del nacionalismo gallego. La continuidad de los diversos partidos y movimientos dentro del BNG reflejaba dos objetivos, uno externo y otro interno. En primer lugar, reflejaba el objetivo de buscar la expansión electoral para ganar votos y asegurar un espacio político en el sistema de partidos gallego. Segundo, el mantenimiento de estas agrupaciones potenciaba la estrategia de fomentar el pluralismo entre diversos grupos y lograr un equilibrio interno que hiciera de contrapeso al poder de la UPG dentro de la estructura del partido (Barreiro, 2003; Lago, 2004).

La superación del umbral de relevancia (en términos de influencia política del BNG) a partir de 1997 tuvo un impacto menor en la organización del partido. Una vez establecido como segunda fuerza en el sistema partidista gallego, el BNG se dedicó a desarrollar nuevos programas y estrategias políticas a nivel autonómico, estatal y europeo. Durante este periodo, no llegaron a ser prioritarios los cambios organizativos, pues la estructura de partido ya se había formalizado y consolidado en la fase anterior. Sin embargo, esta etapa de continuidad duró poco, ya que, en 2001, se produjo una amenaza de retroceso en el recién cruzado umbral de relevancia. El catalizador externo que provocó estos cambios fue el resultado electoral de las elecciones autonómicas de 2001, en las que - por primera vez desde 1985 - tuvo lugar un estancamiento electoral. El BNG y el Partido Socialista obtuvieron la misma representación en el Parlamento gallego, diecisiete escaños, aunque el primero consiguió más $\operatorname{votos}^{13}$. Esta amenaza tuvo un impacto directo en la organización interna del partido en un sentido muy distinto a la fase anterior. La percepción de haber alcanzado un techo electoral y político se tradujo en una serie de conflictos políticos internos en la organización y entre los dirigentes del partido, lo cual se manifestó públicamente en 2002 y 2003, en la X y en la XI asambleas nacionales.

La amenaza de estancamiento tuvo un impacto en la estabilidad del liderazgo y en el equilibrio de poder entre los diversos partidos y colectivos que forman el BNG. Durante casi dos décadas, había permanecido estable el liderazgo del BNG, guiado por Xosé Manuel Beiras, profesor de Económicas y miembro del PSG desde sus comienzos. Aunque era una figura carismática, su

13. El BNG obtuvo un total de 346.430 votos, y el PSdG, 334.819 (Xunta Electoral de Galicia, DOGA, n.o 219, 13-11-2001). 
papel dentro del BNG se limitaba al de portavoz estatal, y nunca ejerció control sobre la organización del partido, por lo que Beiras no encaja en la definición del típico líder carismático de la familia de partidos nacionalistas (De Winter, 1998: 222). Beiras desempeñaba un papel que estaba determinado de antemano por la diversidad de partidos miembros, con un poder limitado debido a la estructura de la UPG. Como líder portavoz del BNG, ofreció estabilidad y continuidad a lo largo de los años ochenta y noventa, una etapa de cambios en la estructura y en la ideología de la coalición. La posibilidad de perder influencia y relevancia política en Galicia fue interpretada dentro del partido, y sobre todo por la UPG, como una señal de que se había alcanzado un techo electoral y político bajo el liderazgo de Beiras, y que se necesitaba una nueva figura política para encabezar el partido. Así, en 2002, en la $\mathrm{X}$ Asamblea Estatal, los dirigentes del BNG establecieron una separación entre los papeles a desempeñar por la figura clave de la ejecutiva o coordinador da Executiva y la figura electoral del portavoz estatal, puestos que fueron ocupados por Anxo Quintana y Beiras, respectivamente. Éste fue el primer paso hacia la sustitución de Beiras como líder del BNG. En la XI Asamblea Nacional del BNG, celebrada en noviembre de 2003 en Santiago de Compostela, se procedió a la sustitución de Beiras, que dejó tanto su anterior puesto de candidato a la presidencia de la Xunta de Galicia, como su puesto de portavoz estatal $^{14}$. Por tanto, en 2003, Quintana se convirtió en candidato a la presidencia y portavoz, a la vez que Beiras ocupaba el puesto de presidente del partido, un cargo creado especialmente para él, de manera que pudiera estar en la ejecutiva del partido ${ }^{15}$, y al que renunciaría el 11 de abril del $2005^{16}$. El resultado fue la elección de un nuevo líder del partido, Anxo Quintana, un joven ex alcalde y senador, un independiente que consiguió el decisivo apoyo de la UPG.

A parte de inducir cambios en el liderazgo de la coalición, se produjo también un reemplazo de las antiguas élites bajo la idea de "renovación y paridad» en la representación del partido en el Parlamento gallego. Con el nuevo líder, entró en el Parlamento gallego una nueva clase política (sólo dos de los miembros del grupo parlamentario del 2005 habían sido elegidos antes). La nueva ejecutiva del partido personifica una nueva generación, pues sólo incluye a dos de los líderes históricos del BNG: Francisco Rodríguez y Xosé Manuel Beiras. En resumen, entre 2001 y 2005, hubo un reemplazo generacional fundamental en el liderazgo del BNG y en sus élites.

14. En esta asamblea, se vio por primera vez más de un candidato: se presentaron Anxo Quintana, el actual portavoz estatal (y que, apoyado por Beiras, obtuvo el $75 \%$ de los votos), y Camilo Nogueira, uno de los líderes históricos del nacionalismo gallego (primero con EG, luego en UG y, finalmente, único eurodiputado del BNG, de 1999 a 2004).

15. La Permanente Estatal es un órgano ejecutivo creado en 1989 y sustituido en 2002 por una ejecutiva estatal que se elige en la Asamblea Estatal.

16. Más tarde, Beiras sería excluido de las listas de candidatos del BNG en las elecciones autonómicas de 2005, al igual que otros muchos históricos del partido. 
Por otra parte, la amenaza de perder relevancia influyó en la estructura del partido, haciendo que se redujese la presencia y el papel de los antiguos partidos y colectivos. El BNG nunca fue una federación de partidos, con cuotas y asignaciones formales de poder, sino una coalición frentista, con representación de los partidos en el Consello Estatal y de modo informal en las listas electorales. En la XII Asamblea, celebrada en el 2002, se redujo el número de representantes en el Consello Nacional, que pasó de dos por partido o colectivo a uno, lo cual implicaba un cambio de equilibrio en su organización. La XII Asamblea Nacional del BNG ya evidenció la existencia de varios conflictos en los antiguos partidos que formaban la coalición ${ }^{17}$.

La amenaza de retroceder el umbral de relevancia también modificó el equilibrio de poder entre grupos dentro del partido y, a consecuencia de ello, ganaron posiciones los «independientes» del BNG. Por primera vez, tuvieron un papel clave que desempeñar los grupos de independientes "organizados» ${ }^{18}$. La afiliación al BNG se hace de manera individual, no por los diversos partidos que lo conforman, y una mayoría de los afiliados son «independientes», en el sentido de que no pertenecen a los diversos partidos y colectivos reconocidos por el BNG ${ }^{19}$. Desde el año 2000, los «independientes no organizados» del BNG se han convertido en un factor a la hora de articular la estructura del partido y de su liderazgo ${ }^{20}$.

En último lugar, la superación del umbral de gobierno tuvo un impacto directo en la organización del partido, lo cual reforzó la dinámica interna previa y la marginalización de los partidos y colectivos, lo cual, a su vez, transformó el pluralismo interno del BNG. Con estos cambios organizativos, los antiguos partidos han perdido posiciones, aunque siguen teniendo una presencia visible. El ejemplo más claro de su supervivencia se vio en la formación del gobierno bipartidista en 2005. El BNG formó un equipo para negociar un pacto de gobierno con el Partido Socialista, un equipo que debía representar a las diversas «almas» y corrientes existentes en el BNG. Este equipo estaba compuesto por tres independientes, cuatro miembros de la UPG, uno

17. Algunos de los antiguos partidos estaban claramente en crisis: tanto EN como UG perdieron a sus líderes históricos, Beiras y Nogueira respectivamente. El apoyo de Beiras a la UPG propició su salida de EN y la articulación de los «independientes de Beiras», mientras sucedía algo parecido en UG, con la salida de otro grupo de independientes, que apoyaban la candidatura de Camilo Nogueira.

18. Aunque en la última asamblea estatal se quedaron sin representación por un puñado de votos, Quintana decidió que el líder de este grupo, Mera, entrara en la ejecutiva a partir de septiembre de 2005.

19. Algunas estimaciones indican que representan por lo menos el $75 \%$ de los afiliados (Vilas y Fernández Baz, 2004; Barreiro, 2003).

20. El líder de los independientes, Roberto Mera, denunció, en la XI Asamblea Nacional, el hecho de que una minoría compuesta por los partidos organizados actuasen por encima de la mayoría de los afiliados del partido, con lo cual proyectaba la imagen de un partido con divisiones internas. En su lugar, propuso que los independientes estuviesen representados como una corriente propia dentro de la organización del partido. 
de EN y uno de Inzar ${ }^{21}$. De todos modos, la presión contraria a la representación de las antiguas organizaciones en el BNG evitó que tuvieran visibilidad en la última Asamblea Nacional, en diciembre de 2006, en la cual se redefinió la naturaleza plural del BNG en varias formas. Por una parte, Quintana y la UPG hicieron pública una lista oficial de candidatos a la Asamblea Nacional del BNG, pero también se organizaron otras tres corrientes con listas alternativas de candidatos: O Incontro Irmandiño, A Alternativa y Movimento pola Base. Las listas de los críticos consiguieron obtener representación tanto en el Consello Estatal como en el Consello Executivo del $\mathrm{BNG}^{22}$. Por tanto, formalmente sigue existiendo una pluralidad de partidos y colectivos, aunque cada vez son más débiles ${ }^{23}$. En resumen, al superar el umbral de gobierno, surgieron presiones adicionales hacia la "normalización" de la organización del partido, en el sentido de unificarlo para dejar atrás el pasado de fuerza frentista. El liderazgo de Anxo Quintana evidencia cual es el actual equilibrio de fuerzas dentro de la estructura de la coalición. Se mantiene el peso tradicional de la UPG, junto con la creciente visibilidad de los independientes y el debilitamiento de los otros partidos y colectivos.

La superación del umbral de gobierno en 2005 tuvo un impacto directo en la eliminación de otra faceta singular de la organización del BNG. A la vez que se produjo el debilitamiento de los colectivos, tuvo lugar una exitosa iniciativa para eliminar el modelo asambleario, que desapareció tras la Asamblea Nacional de 2006, aunque para muchos líderes y miembros del partido era algo que definía la naturaleza organizativa de la coalición desde sus orígenes. Los afiliados del BNG siempre tuvieron el derecho a votar en las asambleas, fueran locales o estatales, aunque no todos llegaban a participar en ellas (Barreiro, 2003) ${ }^{24}$. Anxo Quintana defendió, en la asamblea del partido, la necesidad de sustituir el antiguo modelo asambleario por un sistema de delegados, haciendo hincapié en la necesidad de promover una organización del partido que fuese moderna y eficiente ${ }^{25}$. Así, la Asamblea Nacional de diciembre de 2006 fue la última en usar el sistema de voto directo.

21. Dentro de este grupo, las tres personas con mayor influencia fueron Anxela Bugallo (UG), Francisco Jorquera (UPG) y Carlos Aymerich (un independiente cercano a la UPG).

22. Ahora bien, no se dio en diciembre de 2006 una nueva división entre críticos y oficialistas, que se inclinaban por favorecer al gobierno, ya que se incluyeron a los críticos en los órganos ejecutivos.

23. En la última Asamblea Nacional, las siguientes agrupaciones consiguieron un representante cada uno en el Consello Nacional: UPG, PNG, EN, Nacional, Colectivo Socialista e Inzar.

24. En la Asamblea Nacional de 2003, un total de 2.300 afiliados votaron a favor de la elección de un nuevo portavoz estatal. La propuesta de Ejecutiva Nacional, con una lista unitaria encabezada por Quintana y que incluía a críticos como el mismo Beiras, fue aprobado por 1.634 votos a favor, 71 en contra y 82 abstenciones.

25. Beiras, en cambio, propuso mantener el modelo asambleario, pero perdió la votación, que fue de 1.167 votos en contra de mantenerlo, 803 a favor y 39 abstenciones. 
Es evidente que la presión ejercida tras el estancamiento electoral de 2001, y tras la participación en la coalición de gobierno en 2005, influyó para que, en poco tiempo, se transformaran algunos de los rasgos más emblemáticos de la organización del partido. Incluso antes de la coalición de gobierno ya se notaba una presión a favor de simplificar y «normalizar» la dinámica interna del partido, pero se acentuó cuando el BNG cruzó el umbral de gobierno. La desintegración de los antiguos partidos y colectivos reforzó el desmantelamiento de sus estructuras y de su liderazgo, y este cambio organizativo debilitó el faccionalismo existente en la coalición. Aun así, el pluralismo interno y las voces críticas no han sido eliminados del todo, ni han desaparecido por completo los partidos y los colectivos. Tras la Asamblea Nacional de 2006, el poder sigue estando principalmente en manos de la alianza de la UPG con los independientes, aunque existen otras corrientes y voces representadas en la ejecutiva.

En resumen, los cambios internos y organizativos del partido muestran una adaptación paulatina y constante de la dinámica interna del partido al entorno, con conflictos pero sin cambios abruptos. La superación del umbral de representación (en los tres pasos ya expuestos) determinó que, a lo largo de los años noventa, el BNG se incrementase en complejidad y magnitud organizativa, lo cual consolidó los diversos niveles de su organización. Además, en los años noventa, se definió el carácter de la organización, que estableció la centralidad de la afiliación y la votación directa en las asambleas del partido, con la representación de diversos colectivos en sus órganos ejecutivos. Estos activos organizativos se convirtieron en pasivos o lastres una vez que el partido intuyó que estaba tocando su techo electoral, en 2001. Este shock externo cambió las prioridades organizativas. La nueva dirección se vio reforzada en sus objetivos cuando, en el 2005, se logró alcanzar el umbral de gobierno. A partir de ese momento, el BNG introdujo una serie de reformas sustanciales que minaron la anterior estructura frentista en cuanto a la representación de partidos y el estilo organizativo.

\section{Cambios en los objetivos del partido}

El ciclo de vida del BNG puede describirse como un proceso dinámico en el cual algunos de los objetivos del partido se alcanzaron de forma secuencial. De todos modos, la articulación de los objetivos como tipos ideales — cargos, votos y políticas - ha variado a medida que el BNG cruzaba los diversos umbrales mencionados. Además, durante buena parte del desarrollo del BNG, era posible encaminarse simultáneamente hacia los tres objetivos (políticas públicas, votos y cargos), ya que el sistema de partidos gallego entre 1989 y 2005 presentaba una estructura de oportunidades políticas cerrada. Los ajustes que tuvo que hacer el BNG durante esta etapa fueron de índole menor, y el partido pudo enfocar los tres objetivos sacrificando paulatinamente algunas metas nacionalistas ante la posibilidad de obtener votos y cargos. A medida que el BNG ha cruzado los diversos umbrales de su ciclo vital, se han producido algunos ajustes entre objetivos. 
Tabla 3: Superación de umbrales y cambios en los objetivos del partido

\begin{tabular}{|c|c|c|c|}
\hline Umbrales/niveles & Autonómico & Estatal & Europeo \\
\hline I. Declaración & Políticas públicas & Políticas públicas & Políticas públicas \\
\hline II. Autorización & Políticas públicas & Políticas públicas & Políticas públicas \\
\hline III. Representación & Votos. & $\begin{array}{r}\text { Políticas públicas/ } \\
\text { votos. }\end{array}$ & $\begin{array}{r}\text { Políticas públicas/ } \\
\text { votos. }\end{array}$ \\
\hline IVa. Relevancia & - & - & - \\
\hline IVb. Relevancia & Votos/ & & \\
\hline & cargos públicos. & - & - \\
\hline V. Gobierno & Cargos públicos. & - & - \\
\hline
\end{tabular}

Fuente: elaboración propia.

La tabla 3 detalla la evolución de los objetivos del partido tras superar los diversos umbrales a nivel autonómico, estatal y europeo (Müller y Strom, 1999: 10).

La tabla 3 muestra cómo han evolucionado los objetivos del partido a nivel autonómico tras cruzar cada umbral definido por Pedersen, desde las políticas públicas hasta los cargos públicos. La superación de los umbrales de declaración y autorización no alteró la prioridad política fundamental — la autonomía territorial — durante los primeros años de vida del BNG. Los objetivos del partido cambiaron claramente a nivel autonómico cuando cruzó el umbral de representación, sobre todo cuando superó el llamado tercer umbral de representación, en 1993, con lo cual se convirtió en el único partido nacionalista con representación parlamentaria. Pasó a primera fila el objetivo «votos» y la superación del umbral de relevancia en 1997, cuando, al convertirse en la segunda fuerza política de Galicia, reforzó este comportamiento electoralista. Éste llevó, a su vez, a un mayor énfasis en alcanzar cargos públicos. En la última etapa de la historia del BNG prevalecen los objetivos relacionados con alcanzar cargos públicos.

A nivel estatal y europeo, el ciclo de vida del BNG sólo incluye los umbrales de declaración, autorización y representación. En estas esferas, los cambios de políticas que tuvieron lugar han sido menores. Al principio, los objetivos a nivel estatal y europeo estaban definidos por objetivos en el campo de las políticas públicas: denunciar la situación de Galicia como región atrasada y como nación sin estado dentro de Europa. Desde principios de los noventa, se hicieron más importantes los objetivos relacionados con conseguir votos. A nivel estatal, la superación del umbral de representación en 1996 permitió que los dirigentes del partido hicieran públicas sus exigencias al Gobierno central. El punto de partida en el nivel europeo fue el de mostrar el rechazo del BNG a la UE y los costes económicos y sociales de la integración española para Galicia. Por lo tanto, los objetivos del BNG eran expresivos a nivel europeo, aunque fueron transformándose a lo largo de los años noventa, al igual que los objetivos estatales.

En las fases de evolución de la coalición, se fueron introduciendo una serie de cambios en los objetivos, lo cual modificó su importancia relativa para el partido. Sin embargo, estos cambios se introdujeron de forma gradual y el BNG 
Tabla 4. Resumen de las objetivos del partido a nivel autonómico, a lo largo de su ciclo de vida

\begin{tabular}{lrrr}
\hline Periodo & Políticas públicas & Cargos públicos & Votos \\
\hline $1982-1985$ & Alta & Baja & Baja \\
$1986-1990$ & Alta & Baja & Intermedia \\
$1991-1995$ & Intermedia & Intermedia & Alta \\
$1996-2000$ & Intermedia & Alta & Alta \\
$2001-2005$ & Intermedia & Alta & Intermedia \\
$2006-$ & Intermedia & Alta & Intermedia \\
\hline
\end{tabular}

evitó lo que Müller y Strom tildan de «decisiones difíciles, dolorosas y sustanciales» en la redefinición de los objetivos (Müller y Strom, 1999: 10). El contraste entre los objetivos del BNG se hace evidente al examinar los objetivos a nivel autonómico. La tabla 4 ofrece con mayor detalle las prioridades del BNG a nivel autonómico (en políticas públicas, cargos y votos) durante las diversas etapas. Esta clasificación de objetivos asigna un valor «alto», «intermedio» $\mathbf{O}$ «bajo» al peso de las políticas públicas, los cargos y los resultados electorales como prioridades del partido, de acuerdo con Müller y Strom (1999: 284).

Los primeros años de existencia de este partido frentista estuvieron marcados por el objetivo de la autodeterminación (1982-1985). Esta política inequívoca de defensa de Galicia como nación partía de una postura antisistémica, contraria a reconocer la Constitución española o el Estatuto de Autonomía, ratificada en $1981^{26}$. Sin embargo, la política del BNG se fue redefiniendo de cara al tema de la autonomía territorial. Primero optó por la subordinación de prioridades políticas al objetivo de conseguir avances electorales, ya que su postura militante y antisistema se transformó en 1985 en una estrategia de usar los canales institucionales para fomentar los objetivos del partido. A partir de 1989, el BNG adoptó una postura pragmática, con lo cual moderó su radicalismo para acercarse más al centro del sistema de partidos gallego (Beramendi y Núñez Seixas, 1996; Máiz y Lago, 2004: 34). La superación de los tres umbrales de representación ya definidos permitió que el BNG se dedicase, durante más de una década, a los avances electorales, en conjunción con un proceso de moderación ideológica de las reivindicaciones del partido (19851997). En ningún momento renunció formalmente a los principios políticos de 1982, pero las políticas públicas que respalda el partido se han distanciado perceptiblemente de sus orígenes ideológicos (Máiz, 1996). El llamado Proxecto Común, lanzado a finales de los ochenta, crea una plataforma nacionalista moderada.

Los resultados de las elecciones autonómicas gallegas de 1997 permitieron que el BNG siguiese una estrategia centrada en obtener cargos a nivel auto-

26. Este rechazo se hizo patente en varios conflictos institucionales a lo largo de los años ochenta. Según la primera formulación de Principios Políticos del BNG, hecha en 1982, Galicia es una nación y tiene el derecho a la autodeterminación. 
nómico para culminar sus esfuerzos electoralistas. A partir del año 2000, las prioridades políticas han estado cada vez más subordinadas al objetivo de ocupar cargos públicos. En 2005, el acuerdo del BNG con el PSdG para formar gobierno incluía la reforma del Estatuto de Galicia y el reconocimiento de Galicia como nación, aunque, una vez en el gobierno, la reforma del Estatuto ocupó un lugar secundario. En síntesis, a nivel autonómico, el ciclo de vida del BNG muestra la subordinación de las políticas públicas del BNG a sus objetivos electorales y de gobierno.

Tras superar el umbral de gobierno en 2005, el BNG se involucró activamente en la elaboración del nuevo Estatuto de Autonomía de Galicia, siguiendo los pasos del proceso político en Cataluña. La reforma del Estatuto gallego fue incluida formalmente en el pacto de gobierno entre el PSdG y el BNG en 2005, pues con este acuerdo se buscaba reconocer el carácter de Galicia como nación. El BNG elaboró una propuesta de estatuto de autonomía, que presentó de manera oficial en diciembre de $2005^{27}$. La propuesta de estatuto del BNG fue diseñada antes del final del proceso político en Cataluña, cuyo nuevo estatuto fue ratificado el 18 de junio de $2006^{28}$.

Sin embargo, la postura programática del BNG en temas de autonomía se ha hecho cada vez más flexible. Desde el 2005, el BNG ha transigido en el pacto de gobierno en cuanto al reconocimiento del "carácter de nación» de Galicia, lo cual ha diluido su énfasis en la nación. Tras el debate sobre el estado de las autonomías (3 y 4 de octubre de 2006), el líder del BNG dejó claro que su prioridad era alcanzar acuerdos con otras fuerzas políticas. Usando el ejemplo del nuevo estatuto de autonomía de Cataluña, se redefine el término «nación» en el preámbulo de la propuesta del BNG, que establece: «la tradición, el sentimiento y el Parlamento definen a Galicia como nación», y que incluye seguidamente el artículo 2 de la Constitución española, que reconoce a Galicia como una nacionalidad histórica. Para Quintana, ésta sería la fórmula para insertar el nuevo estatuto en el marco de la Constitución española. Más importante aún, el líder del BNG declaró, a lo largo del proceso, que ninguna de sus posturas estaban fijas o por encima de la negociación, y que el partido estaba dispuesto a alcanzar acuerdos. A pesar de su buena disposición, en enero de 2007, se estancaron sine die las negociaciones entre los tres partidos, el BNG, el PSdG y el PP. El fracaso en los intentos por llegar a un acuerdo sobre la reforma del Estatuto de Autonomía recae, en última estancia, sobre el PP de Galicia, que bloqueó las negociaciones en enero del 2007. El BNG puede alegar a este respecto que, a pesar de sus esfuerzos por moderar su pos-

27. Esta propuesta fue muy criticada por diversas razones, empezando por el artículo que dice:

«La nación de Galicia constituye una comunidad política [...] y está integrada como Comunidad Autónoma dentro del Estado español.»

28. El proceso político catalán también marcó los debates en Galicia, ya que las propuestas de reforma del Estatuto están claramente influidas por los artículos del Estatuto Catalán, sobre todo los más controvertidos, en torno a la nación. 
tura política en cuestiones de autonomía, el proceso fracasó debido a la postura del PP.

Por último, las propuestas programáticas del BNG muestran la naturaleza dual del BNG como organización nacionalista y de izquierdas. La evolución ideológica del partido frentista modificó su naturaleza, que pasó a principios de los ochenta de ser una organización de extrema izquierda a una de izquierdas moderada. El programa original de 1982 incluía propuestas antimonopolistas en defensa de los intereses del pueblo y el principio de autogestión estatal (sindicatos, partidos) contra el colonialismo político. Una vez en el gobierno, el BNG ha buscado equilibrar los dos elementos principales de su ideología: la autonomía y la solidaridad territorial, y las políticas sociales. Cada vez ha prestado más atención a éstas últimas en sus objetivos de acción.

En resumen, durante el desarrollo del BNG, los líderes del partido tuvieron que tomar decisiones sobre los objetivos a medida que la coalición cruzaba diversos umbrales a nivel autonómico, estatal y europeo, decisiones que no resultaron ser especialmente "duras» en términos de conflictos internos. Ahora bien, las decisiones «menos duras» también tienen consecuencias en la dinámica interna del partido y en sus objetivos. El afán por entrar en el Gobierno llevó a los dirigentes del BNG a tomar ciertas decisiones con el fin de alcanzar cargos políticos; el precio a pagar ha incluido la salida de los antiguos líderes, el debilitamiento del equilibrio entre las diversas corrientes internas del partido y, finalmente, una pérdida de votos y escaños en el Parlamento de Galicia.

\section{Conclusiones}

El BNG representa uno de los ejemplos más evidentes de éxito electoral e institucional dentro de la familia de partidos nacionalista en Europa. En veinticinco años de historia, ha pasado de la marginalidad electoral al Gobierno autonómico. El éxito, la entrada en una coalición de gobierno, representa un objetivo histórico y considerado de largo plazo en Galicia, debido a la debilidad secular de los partidos nacionalistas en esta "nacionalidad histórica». El ciclo vital del BNG de la marginalidad al gobierno tiene una fase clave: la superación de los tres umbrales de representación a nivel autonómico (cuando obtiene representación en el Parlamento gallego, con lo cual se convierte en la primera fuerza nacionalista del Parlamento autonómico y llega, finalmente, a ser el único partido nacionalista con representación). Este proceso ha definido un espacio político singular para el nacionalismo gallego, pues sería difícil volver atrás en cuanto a la actual coordinación entre partidos nacionalistas en Galicia. La secuencia de cambios y las decisiones tomadas hacen que sea improbable que se vuelva a la fragmentación de partidos nacionalistas que marcó la primera etapa de la democracia y que se extendió durante los años setenta y ochenta.

En relación con el impacto de estas fases en la vida del BNG, el artículo ha mostrado sus efectos, tanto en la organización como en los objetivos del partido. Por un lado, el BNG siempre se ha definido por la naturaleza plural de 
su organización, que ha integrado a los diversos partidos nacionalistas de Galicia bajo un partido frentista, y ha ofrecido a cambio la posibilidad de representación en sus órganos ejecutivos. El debilitamiento de los mecanismos de representación de estos grupos y colectivos en la etapa más reciente ha minado una de las facetas más características de la organización del partido. La superación del umbral de gobierno dio lugar a una presión adicional sobre la estructura de la coalición. No sólo se modificó la estructura de representación plural de partidos y colectivos, sino que, en diciembre de 2006 —en la última Asamblea Estatal- se eliminó el modelo asambleario. Por otro lado, en términos de objetivos, la superación de los diversos umbrales determinó que el programa autonomista del partido se fuera moderando y se privilegiaran los objetivos electorales y de cargos públicos. Más tarde, al cruzar el umbral de gobierno, los objetivos autonomistas del partido se han moderado para dejar lugar a acuerdos y políticas de gobierno centrados en la política social.

La perspectiva a largo plazo muestra que las decisiones tomadas por los dirigentes del partido fueron exitosas — si se miden en términos de puestos de gobierno-y no resultaron excesivamente «duras» (ya que el precio pagado por los líderes del BNG no fue de gran calado y la estructura de la coalición retuvo su unidad). Ahora bien, a corto plazo, cada uno de los pasos del ciclo vital y su secuencia estuvieron marcados por tensiones internas dentro del partido. En la última Asamblea Nacional, estas diferencias se resolvieron por medio de la incorporación a la ejecutiva de los sectores críticos. Así, las decisiones más recientes y controvertidas de la cúpula del partido no han modificado el actual equilibrio entre los tres objetivos básicos. De todos modos, el equilibrio entre objetivos no está dado de antemano, y puede cambiar dependiendo de factores internos y externos. En las próximas elecciones, el electorado juzgará, entre otras cosas, el rendimiento del BNG en el Gobierno gallego.

\section{Bibliografía}

AdAMS, J.; Clark, M.; EZrow, L.; GlasGow, G. (2006). «Are Niche parties fundamentally different from Mainstream parties? The causes and the electoral consequences of Western European parties Policy Shifts, 1976-1998». American Journal of Political Science, vol. 50: 3, julio, 513-529.

BARREIRO RIVAS, J. (2003). «Da UPG ao BNG: o proceso organizativo do nacionalismo galego». En: Rivera Otero, Xosé Manuel (ed.). Os partidos políticos en Galicia. Vigo: Xerais.

BERAMENDI, J. G.; NúNEZ SEIXAS, E. (1996). O nacionalismo galego. 2a ed. Edicions A Nosa Terra.

De Winter, L.; GÓMEZ-Reino M.; LynCH, P. (2006). Autonomist parties in Europe: Identity politics and the revival of the territorial cleavage. Barcelona: ICPS.

DE WINTER, L.; TÜrSAN, H. (1998). Autonomist parties in Western Europe. Londres: Routledge.

De Winter, L.; Gómez-Reino, M. (2002). «European Integration and Ethnoautonómicoist Parties». Party Politics, vol. 8, n. o 4, 483-503. 
ELIAS, Anwen (2005). Europeanising the nation. Minority nationalist responses to European Integration: Wales, Galicia and Corsica. EUI. Unpublished dissertation.

FERNÁNDEZ BAZ, M. A. (2003). A formación do nacionalismo galego contemporáneo (1963-1984). Santiago de Compostela: Laiovento.

Fraile, Marta; PÉREZ-NiEvas, Santiago (2000). Is nationalist vote really nationalist? Dual voting in Catalonia 1980-1990. Instituto Juan March, WP 147/2000.

Gómez-Reino, M. (2006). "The Galician BNG from outcast to success». En: DE Winter, L.; GÓmEZ-Reino, M.; LYNCH, P. Autonomist parties in Europe: Identity politics and the revival of the territorial cleavage. Barcelona: ICPS.

JIMÉNEZ, Fernando (2003). «O PSdG-PSOE, un caso de débil institucionalización», en Rivera Otero, Xosé Manuel (coord.). Os partidos politicos en Galicia. Vigo: Xerais.

KATZ, R.; MAIR, P. (1994). How parties organize. Change and adaptation in party organizations in Western democracies. Londres: Sage.

Lagares, Nieves (2003). «O Partido Popular de Galicia». En: Xosé Manuel Rivera OTERO (coord.). Os partidos politicos en Galicia. Vigo: Xerais.

LAGO, I. (2000). "Identidades duales y abstención diferencial en las comunidades autónomas: los casos de Cataluña, Galicia y País Vasco». Dereito, vol. 9, n. ${ }^{2}$, 83-103.

- (2004). «La coordinación electoral del nacionalismo gallego». Revista Interestatal de Sociología, n. 39, septiembre-diciembre, 35-61.

Lago, I.; LaGO, S. (2006). Vinte e cinco anos de autonomía politica en Galicia: mudanzas políticas e económicas. Santiago de Compostela: Escola Galega de Administración Pública.

LAGO, I.; MÁız, R. (2004). «Le nationalisme galicien: opportunités, mobilisation politique et coordination électorale». Pôle Sud, n. o 20, mayo, 25-46.

LlamaZARES, Iván; GÓmEZ-REINO, Margarita; RAMIRO, Luis (2007). «Euroscepticism and political parties in Spain». En: TAGGART, Paul; SzCERBIAK, Alex (eds.). Opposing Europe? The Comparative party politics of euroscepticism. Oxford: Oxford University Press, próximamente.

Márz, R. (1996). «Nación de Breogán: Oportunidades políticas y estrategias enmarcadoras en el movimiento nacionalista gallego (1886-1996)». Revista de Estudios Políticos, n. ${ }^{\circ}$ 92, abril-junio, p. 33-75.

- (1994). "The open-ended construction of a nation: the Galician case in Spain». En: Beramendi, Justo G.; MÁIZ, Ramón; NúNEzZ SeIXAS, Xosé (eds.). Nationalism in Europe. Past and present. Santiago de Compostela: Universidade de Santiago de Compostela, 173-208.

MÁrquez Cruz, G. (2000). "Los gobiernos de coalición en Galicia». En: MATAS, Jordi (ed.). Coaliciones politicas y gobernabilidad. Barcelona: ICPS.

Meguid, B. (2005). "Competition among unequals. The role of Mainstream parties in Niche party success». American Political Science Review, vol. 99, n. ${ }^{\circ}$ 3, agosto, 347-359.

Montero, José Ramón; FonT, Joan (1991). «El voto dual en Cataluña: lealtad y transferencias de voto en las elecciones autonómicas». Revista de Estudios Políticos, n. ${ }^{\circ} 73,7-34$.

Müller, W. C.; Strom, K. (1999). Policy, office, or votes? How political parties in Western Europe make hard decisions. Cambridge: Cambridge University Press.

MÜllER-ROMMEL, Ferdinand (2002). Green parties in national governments. London: Frank Cass. 
PEDERSEN, Mogens (1982). «Towards a new typology of party life-spans and minor parties». En: MÜller-Rommel, Ferdinand; PridHAM, Geoffrey (eds.). Small parties in Western Europe. Londres: Sage.

ReIF, K.; SCHMIT, H. (1980). «Nine european second order elections». En: European Journal of Political Research, vol. 8, 3-44.

RibA, Clara (2000). «Voto dual y abstención diferencial: un estudio sobre el comportamiento electoral en Cataluña». Revista Española de Investigaciones Sociológicas, n. ${ }^{\circ} 91,59-88$.

Riera, Pedro (2007). La participación pendular: abstención diferencial en la España autonómica: los casos del País Vasco, Galicia y Cataluña en el ciclo electoral 20052006. Ponencia presentada en la AECPA, 18-20 de septiembre.

Rivera Otero, X. M. (2003). "Comportamiento electoral e sistema de partidos en Galicia». En: Rivera Otero, X. M. (coord.). Os partidos políticos en Galicia. Vigo: Xerais.

Rivera Otero, X. M.; Lagares Diez, N.; Castro Duarte, A.; Diz Otero, I. (1998). "Las elecciones autonómicas en Galicia». En: AlCÁNTARA, M.; MARTíneZ, A. (eds.), 15 Años de elecciones autonómicas en España. Madrid: CIS.

SARTORI, Giovanni (1976). Parties and party systems. A framework for analysis. Cambridge: Cambridge University Press.

Vilas Nogueira, J.; Fernández Baz, M. A. (2004). «El BNG: Definición y evolución de su estructura organizativa». Revista de Estudios Politicos, n. ${ }^{\circ}$ 123, 201-222.

Vilas Nogueira, J. (1992). "Las elecciones autonómicas en Galicia (1981-1990)». Revista de Estudios Políticos (nueva época), n.o 75, enero-marzo, 59-85. 